\title{
Raman Spectroscopy of Isotactic Polypropylene-Halloysite Nanocomposites
}

\author{
Elamin E. Ibrahim, ${ }^{1}$ Dorina Magdalena Chipara, ${ }^{2}$ Ram Thapa, ${ }^{2}$ \\ Karen Lozano, ${ }^{3}$ and Mircea Chipara ${ }^{2}$ \\ ${ }^{1}$ Department of Chemistry, The University of Texas-Pan American, Edinburg, TX 78541, USA \\ ${ }^{2}$ Department of Physics and Geology, The University of Texas-Pan American, 1201 West University Drive, Edinburg, TX 78541, USA \\ ${ }^{3}$ Department of Mechanical Engineering, The University of Texas-Pan American, Edinburg, TX 78541, USA
}

Correspondence should be addressed to Dorina Magdalena Chipara, dchipara@utpa.edu

Received 15 June 2012; Revised 20 August 2012; Accepted 3 September 2012

Academic Editor: Steve F. A. Acquah

Copyright (c) 2012 Elamin E. Ibrahim et al. This is an open access article distributed under the Creative Commons Attribution License, which permits unrestricted use, distribution, and reproduction in any medium, provided the original work is properly cited.

\begin{abstract}
Raman spectroscopy investigations on nanocomposites obtained by dispersing halloysite within isotactic polypropylene are reported. A detailed analysis of the modifications of the regularity band associated to the polymeric matrix is presented. The Raman lines assigned to the polymeric matrix are broadened and weakened as the loading with halloysite is increased. The analysis of Raman lines indicates that the polymeric matrix becomes less crystalline upon the loading with halloysite and that the nanofiller is experiencing a weak dehydration upon dispersion within the polymeric matrix, probably due to the related thermal processing used to achieve the dispersion of halloysite.
\end{abstract}

\section{Introduction}

The dispersion of carbon nanotubes within polymeric matrices resulted in important improvements of the mechanical properties (reflected in most cases by increases of the Young modulus [1-4]) and of the thermal stability [4] of polymeric matrices. Nevertheless, the electrical and thermal conductivity of one-dimensional carbon nanostructures [5, 6] added thermal and electrical conductivity to the typically insulating polymeric matrices (especially if the concentration of the nanofiller is at or above the percolation threshold $[7,8])$. For some applications, such as electrical insulators or thermal barrier materials, such modifications are adverse. Detailed investigations on isotactic polypropylene filled with other one-dimensional materials (such as single-walled carbon nanotubes, multiwalled carbon nanotubes, and carbon nanofibers) have been reported elsewhere [9-13].

Halloysite $(\mathrm{H})$ is an unique nanoclay [14], with a tubular morphology and low electrical and thermal conductivity. These features incited several investigations on the physical properties of polymer-halloysite nanocomposites [14-17].
Taking into account the above-mentioned characteristics, a detailed investigation on the physical properties of isotactic polypropylene-halloysite nanocomposite has been ignited.

There are several types of halloysites, corresponding to the degree of hydration. The extremes are represented by the so-called halloysite $10 \mathrm{~A}$, and by halloysite $7 \mathrm{~A}$. Halloysite $10 \mathrm{~A}$ is characterized by a monoclinic crystalline structure (with the cell parameters $a=5.1 \mathrm{~A}, b=8.9 \mathrm{~A}$, $c=10.25 \mathrm{~A}$, and $\beta=100^{\circ}$ ), with the chemical formula $\mathrm{Al}_{2} \mathrm{Si}_{2} \mathrm{O}_{5}(\mathrm{OH})_{4} 2 \mathrm{H}_{2} \mathrm{O}$ and the unit cell volume of about $458 \mathrm{~A}^{3}$. Halloysite $10 \mathrm{~A}$ is a nanotube with diameters ranging typically between 30 to $200 \mathrm{~nm}$, a wall thickness of $20 \mathrm{~nm}$, and lengths ranging between $500 \mathrm{~nm}$ to $10,000 \mathrm{~nm}$ obtained by rolling together kaolinite like sheets. It is known also as endelite, hydrated halloysite, or hydrohalloysite. It is typically unstable having a strong tendency to loose water. Halloysite $7 \mathrm{~A}$ (with amonoclinic crystal structure and cell parameters $a=5.14 \mathrm{~A}, b=8.9 \mathrm{~A}, c=14.9 \mathrm{~A}$, and $\beta=101.9^{\circ}$ ) has an unit volume of about $667 \mathrm{~A}^{3}$ and it is known as the dehydrated halloysite. During the dehydration process, the distance between layers decreases from about $1 \mathrm{~nm}$ to $0.7 \mathrm{~nm}$. 


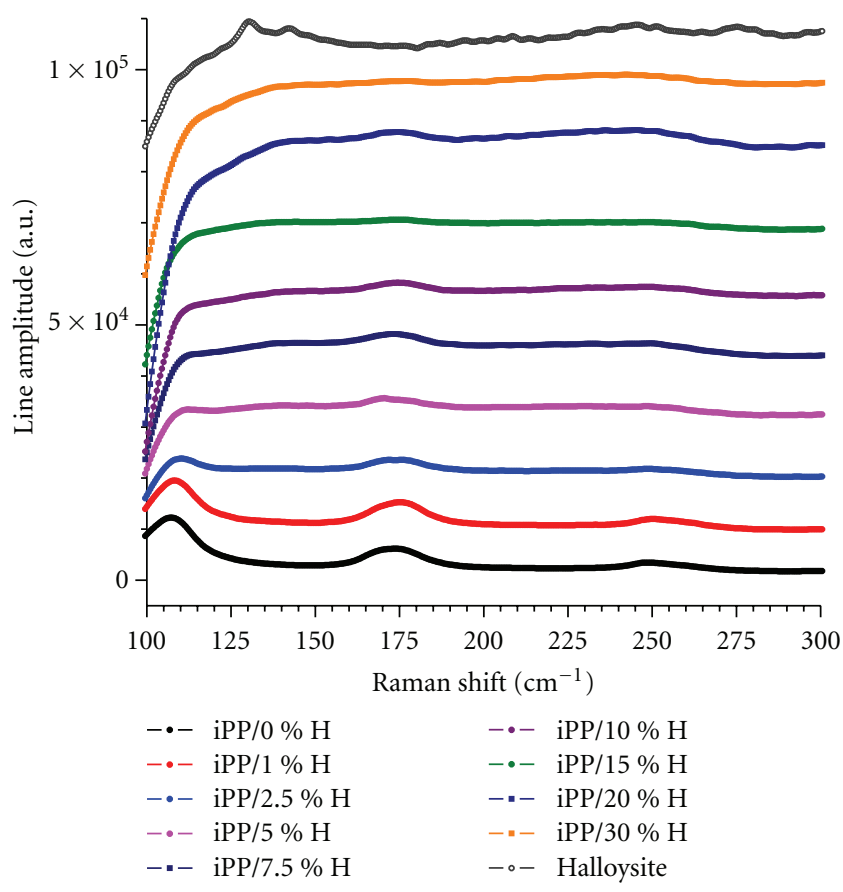

FIGURE 1: Raman spectra of iPPH nanocomposites for different loadings with $\mathrm{H}$. From bottom to top: $0 \% \mathrm{H}, 1.0 \% \mathrm{H}, 2.5 \% \mathrm{H}, 5.0 \%$ $\mathrm{H}, 7.5 \% \mathrm{H}, 10.0 \% \mathrm{H}, 15 \% \mathrm{H}, 20 \% \mathrm{H}, 30 \% \mathrm{H}$, and $100 \% \mathrm{H}$.

In halloysite, strong hydrogen interactions are responsible for the enhanced stability of hole water compared to associated water. Typically, the associated water is released at about $200^{\circ} \mathrm{C}$, while the hole water survives up to about $300^{\circ} \mathrm{C}$. The dehydrated halloysite is also known as metahalloysite. Several aluminosilicates (clays) have the same elemental composition $\mathrm{Al}_{2} \mathrm{Si}_{2} \mathrm{O}_{5}(\mathrm{OH})_{4}$ as the dehydrated halloysite. Among them, the most important are (in alphabetical order) dickite, kaolinite, and nacrite. These compounds differ solely by the spatial distribution of atoms and consequently the discrimination between halloysite and any of these compounds is frequently difficult.

\section{Experimental Methods}

The structure and composition of naturally occurring $\mathrm{H}$ is expected to be intermediate between $7 \mathrm{~A}$ and $10 \mathrm{~A}$, reflecting an $\mathrm{Al}_{2} \mathrm{Si}_{2} \mathrm{O}_{5}(\mathrm{OH})_{4} \cdot x \mathrm{H}_{2} \mathrm{O}$ chemical formula where $x$ is close to zero but not precisely zero due to some crystallization water eventually retained. This derives from the fact that most dehydrated halloysite $(7 \mathrm{~A})$ result from the dehydration of halloysite $(10 \mathrm{~A})$. Isotactic polypropylene-halloysite (iPPH) nanocomposites were obtained by high-shear mixing of isotactic polypropylene (iPP; Sigma Aldrich) with various amounts of halloysite $\left(\mathrm{Al}_{2} \mathrm{Si}_{2} \mathrm{O}_{5}(\mathrm{OH})_{4} \cdot x \mathrm{H}_{2} \mathrm{O}\right.$; from Sigma Aldrich). Kaolinite, with a close chemical structure (missing, however, the two water molecules, i.e., $\left.\mathrm{Al}_{2} \mathrm{Si}_{2} \mathrm{O}_{5}(\mathrm{OH})_{4}\right)$, is sometimes also referred to as a halloysite (see, e.g., the website of Sigma Aldrich http://www.sigmaaldrich.com/catalog/ product/aldrich/685445?lang=en\&region=US) or as metahalloysite. The cylindrical symmetry of halloysite $(\mathrm{H})$ is

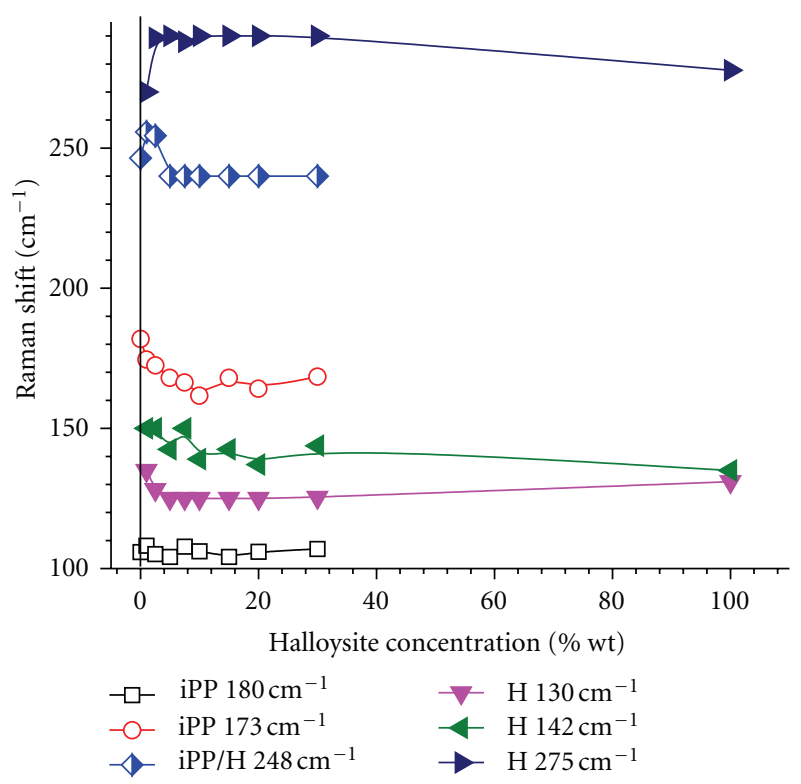

FIGURE 2: The effect of the loading with $\mathrm{H}$ on the position of Raman lines in the range from 100 to $300 \mathrm{~cm}^{-1}$. iPP (or open symbols) identifies the Raman lines assigned to the matrix, and $\mathrm{H}$ the Raman lines due to the filler. Half-filled symbols represent overlapping lines due to iPP and $\mathrm{H}$.

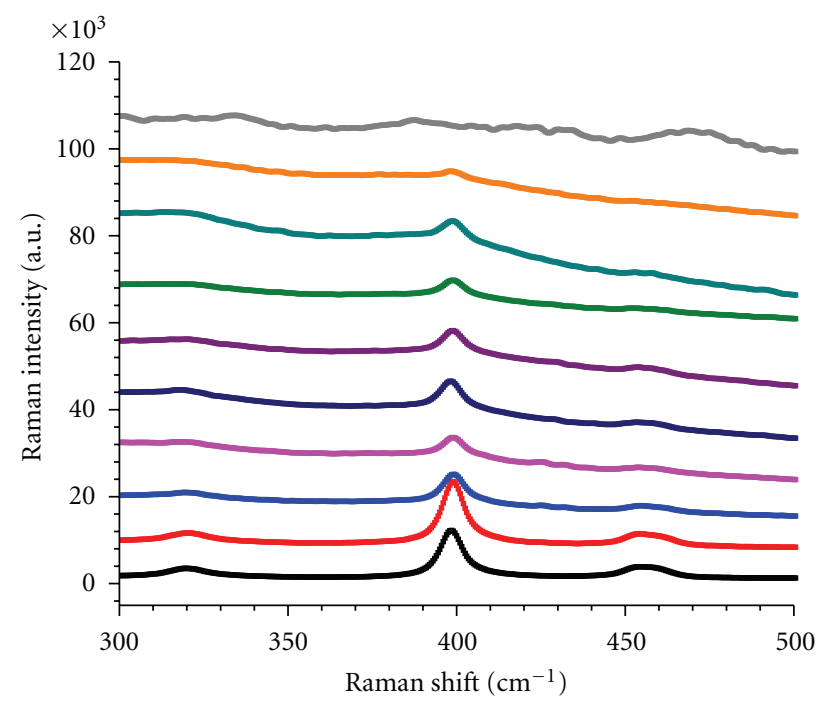

FIgURE 3: Raman spectra of iPPH nanocomposites for different loadings with $\mathrm{H}$. From bottom to top: $0 \% \mathrm{H}, 1.0 \% \mathrm{H}, 2.5 \% \mathrm{H}, 5.0 \%$ $\mathrm{H}, 7.5 \% \mathrm{H}, 10.0 \% \mathrm{H}, 15 \% \mathrm{H}, 20 \% \mathrm{H}, 30 \% \mathrm{H}$, and $100 \% \mathrm{H}$.

a consequence of a packing disorder. According to Sigma Aldrich, the external diameter of halloysite nanotubes is ranging between 30 and $70 \mathrm{~nm}$ (with an average of $50 \mathrm{~nm}$ ), the average internal diameter is about $15 \mathrm{~nm}$, and the length of halloysite is typically ranging between 1 to $3 \mu \mathrm{m}$. Hence, halloysite nanotubes are comparable to short-multiwalled carbon nanotubes. However, the Young modulus, the electrical conductivity, the thermal conductivity, and the thermal stability of halloysite are significantly lower than those 


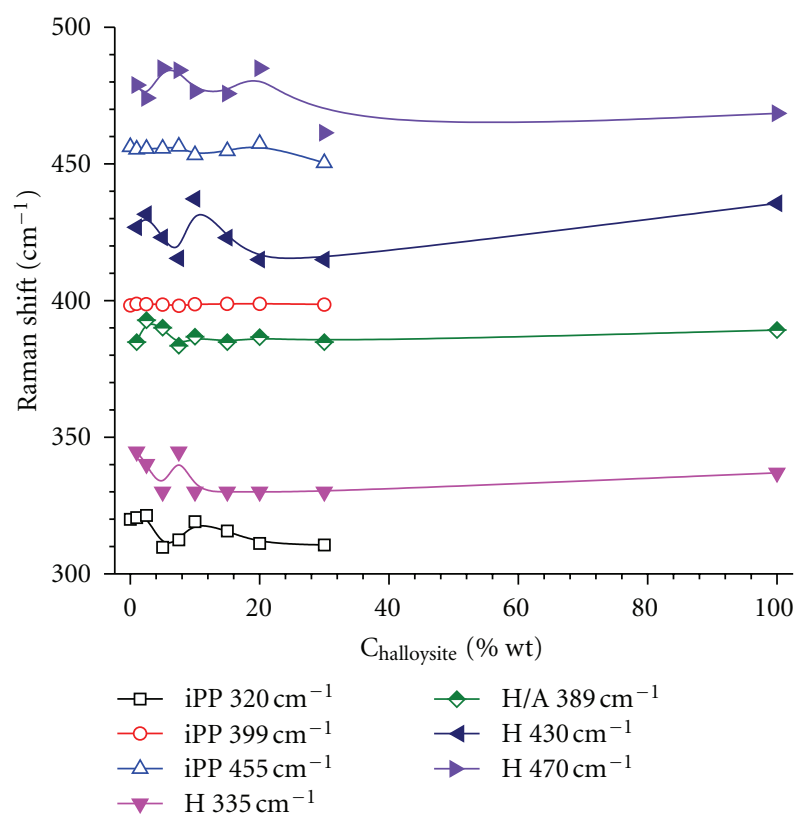

FIgURE 4: The effect of the loading with $\mathrm{H}$ on the position of Raman lines in the range from 300 to $500 \mathrm{~cm}^{-1}$. iPP (or open symbols) identifies the Raman lines assigned to the matrix, and $\mathrm{H}$ the Raman lines due to the filler. Half-filled symbols represent overlapping lines due to $\mathrm{iPP}$ and $\mathrm{H}$.

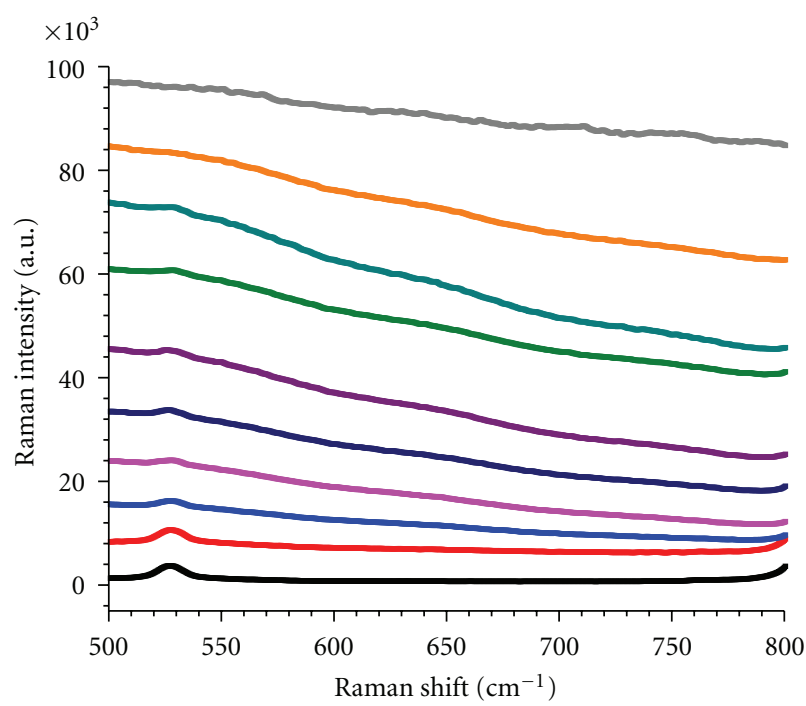

FIGURE 5: Raman spectra of iPPH nanocomposites for different loadings with $\mathrm{H}$. From bottom to top: $0 \% \mathrm{H}, 1.0 \% \mathrm{H}, 2.5 \% \mathrm{H}, 5.0 \%$ $\mathrm{H}, 7.5 \% \mathrm{H}, 10.0 \% \mathrm{H}, 15 \% \mathrm{H}, 20 \% \mathrm{H}, 30 \% \mathrm{H}$, and $100 \% \mathrm{H}$.

of multiwalled carbon nanotubes. The estimated Young modulus of halloysite is in the range from 150 to $300 \mathrm{GPa}$ compared to $1000 \mathrm{GPa}$ for a carbon nanotube [18]. The energy gap for halloysite is of about $9.7 \mathrm{eV}$ compared to few $\mathrm{eV}$ (or zero) in semiconducting or metallic carbon nanotubes [18]. This classifies halloysite as an electric insulator.

The blending has been performed by utilizing a HAAKE Rheomix at $65 \mathrm{rpm}$ and $180^{\circ} \mathrm{C}$ for 9 min followed by an

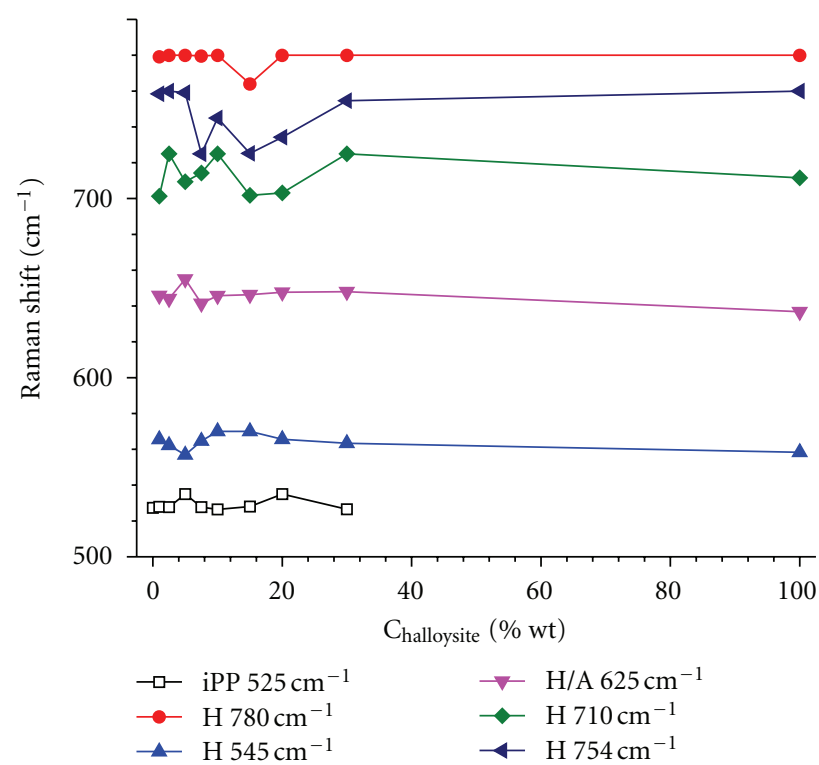

FIGURE 6: The effect of the loading with $\mathrm{H}$ on the position of Raman lines in the range 500 to $800 \mathrm{~cm}^{-1}$. iPP (or open symbols) identifies the Raman lines assigned to the matrix, and $\mathrm{H}$ the Raman lines due to the filler. Half-filled symbols represent overlapping lines due to iPP, $\mathrm{H}$, and $\mathrm{A}$.

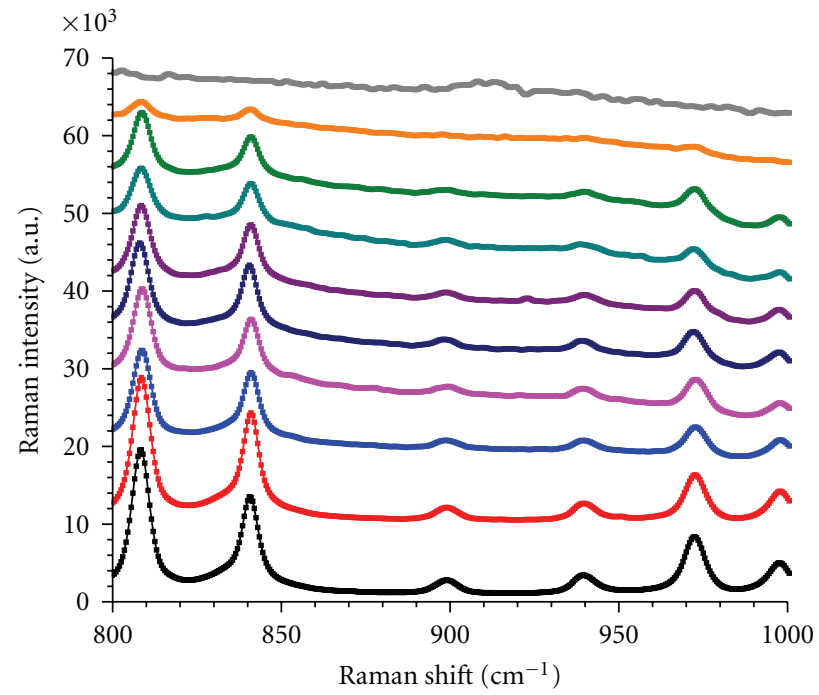

FIGURE 7: Raman spectra of iPPH nanocomposites for different loadings with $\mathrm{H}$. From bottom to top: $0 \% \mathrm{H}, 1.0 \% \mathrm{H}, 2.5 \% \mathrm{H}, 5.0 \%$ $\mathrm{H}, 7.5 \% \mathrm{H}, 10.0 \% \mathrm{H}, 15 \% \mathrm{H}, 20 \% \mathrm{H}, 30 \% \mathrm{H}$, and $100 \% \mathrm{H}$.

additional mixing of $5 \mathrm{~min}$ at the same temperature and at $90 \mathrm{rpm}$. Composites loaded with various amounts of $\mathrm{H}$ ranging from $0 \%$ up to $30 \% \mathrm{wt}$. have been prepared. Raman investigations have been performed by using a Bruker Senterra dispersive confocal microscope spectrometer equipped with a $785 \mathrm{~nm}$ laser diode. Thermogravimetric analysis has been performed in nitrogen atmosphere by using a TA Instrument Equipment. 


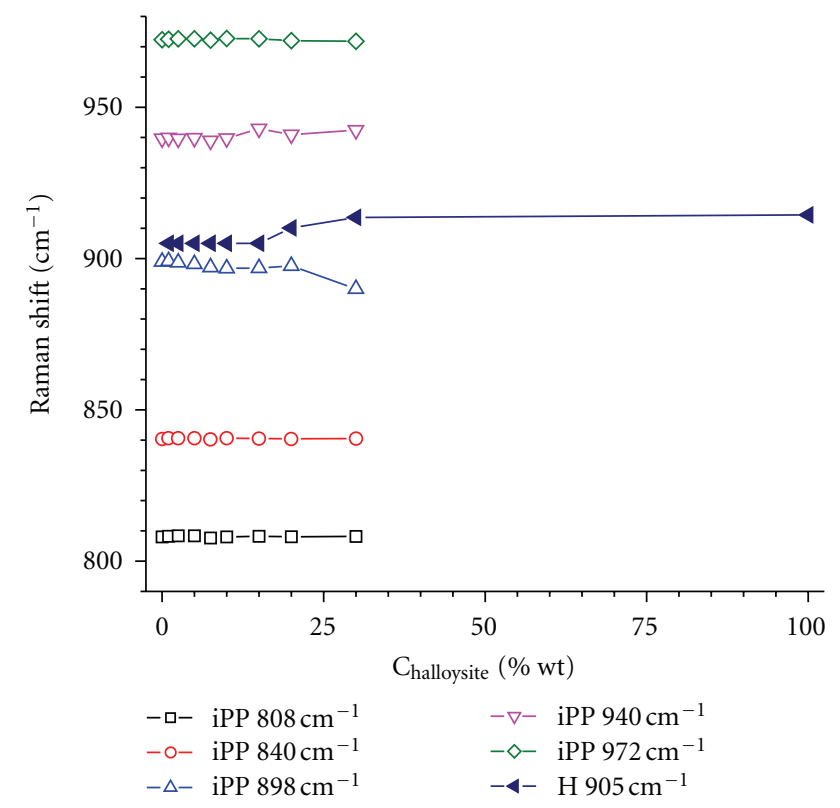

Figure 8: The effect of the loading with $\mathrm{H}$ on the position of Raman lines in the range from 800 to $1000 \mathrm{~cm}^{-1}$. iPP (or open symbols) identifies the Raman lines assigned to the matrix, and $\mathrm{H}$ the Raman lines due to the filler.

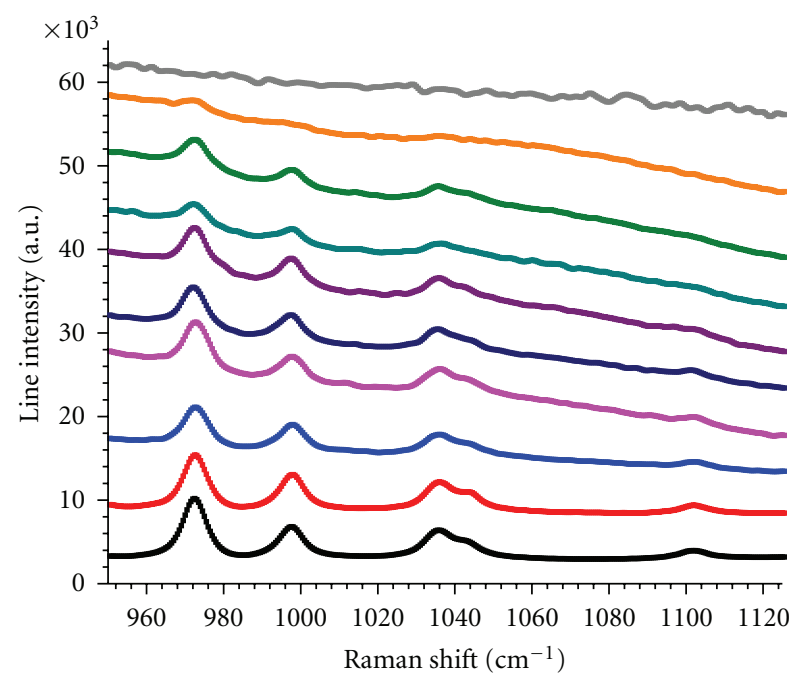

FIGURE 9: Raman spectra of iPPH nanocomposites for different loadings on the position of Raman lines in the range from 800 to $1000 \mathrm{~cm}^{-1}$. iPP (or open symbols) identifies the Raman lines assigned to the matrix, and $\mathrm{H}$ the Raman lines due to the filler. Halffilled symbols represent overlapping lines due to iPP and $\mathrm{H}$.

\section{Experimental Results and Discussions}

The Raman lines of pristine $\mathrm{H}$ are rather broad and weak, being superimposed on a very strong and wideband noticed at low Raman shifts (centered at about $125-150 \mathrm{~cm}^{-1}$ and reported as a shoulder assigned to $\mathrm{O}-\mathrm{Si}-\mathrm{O}$ bending [19]). The Raman lines of iPP are typically narrow lines. As in the case of iPP-Vapor Grown Carbon Nanofiber (VGCNF) nanocomposites [11], the addition of the filler broadens the
Raman lines of the polymeric matrices up to their collapse in a very broad line. This behavior reflects the formation of an interface between the nanofiller and the polymeric chains and the final trapping of most macromolecular chains within these interfaces at loading concentrations above $20 \% \mathrm{wt}$.

All Raman lines have been fitted by a superposition of modified Wigner-Breit-Fano lineshapes [20]; the general expression utilized for each line was

$$
I(x)=\sum_{i=1}^{N} A_{i} \frac{\left[1+D_{i}\left(x-P_{i}\right) / W_{i}\right]^{2}}{1+\left[\left(x-P_{i}\right) / W_{i}\right]^{2}}+B+S x+Q x^{2},
$$

where $I$ is the amplitude of the Raman spectral domain at a given Raman shift $x$ (in $\mathrm{cm}^{-1}$ ), $N$ is the total number of lines for the spectral domain (including eventually both iPP and $\mathrm{H}$ lines), $B$ is the base line correction, $S$ is the slope correction, and $Q$ is a quadratic correction. For each line, labeled by $i, D_{i}$ is the shape deviation from a pure Lorentzian line, $P_{i}$ is the corresponding Raman peak position, and $W_{i}$ is the width of the line. For each spectral domain, an excellent agreement between fitted and recorded spectra was achieved, with correlation coefficients typically above 0.99 . Each spectral domain involved at least 250 experimental points. The fit has been performed by using Origin Pro 8.6.

At low wavenumbers (spectral domain 100 to $300 \mathrm{~cm}^{-1}$ ), the Raman spectrum shows the typical lines reported elsewhere (see Figure 1). The broad shoulder reported in the range from 110 to $130 \mathrm{~cm}^{-1}$ is easily noticed in Figure 1 . Raman spectra of halloysite confirm the line located at $130.8 \mathrm{~cm}^{-1}$ identified as the line noticed at $134.7 \mathrm{~cm}^{-1}$ and assigned to the symmetric (out of the plane) bending mode of $\mathrm{Si}_{2} \mathrm{O}_{5}[21,22]$. Tentatively, this can be associated to the line reported at $127 \mathrm{~cm}^{-1}$ in the New Zeeland halloysite [23]. An intense line was noticed at $142.4 \mathrm{~cm}^{-1}$ and identified as the line reported at $143 \mathrm{~cm}^{-1}$ [23]. The origin of this line is under debate. Some authors are assigning this line to anatase impurities [19] while others are assigning this line to $\mathrm{AlO}_{6}$ octahedron vibrations [22]. The Raman lines at 156 and $168 \mathrm{~cm}^{-1}$ connected to inner surface hydroxyls are absent, suggesting a low degree of hydration [21]. However, the weak lines observed at $246(\mathrm{O}-\mathrm{H}-\mathrm{O}$ symmetric stretch in hydrated halloysite [24]) and $276 \mathrm{~cm}^{-1}(\mathrm{O}-\mathrm{H}-$ $\mathrm{O}$ antisymmetric stretch in hydrated halloysite [24]) are connected to water's molecule vibrations [22].

For isotactic polypropylene, the lines located at $108 \mathrm{~cm}^{-1}$, $173 \mathrm{~cm}^{-1}$, and $248 \mathrm{~cm}^{-1}$ are easily noticed. The Raman line located at $248 \mathrm{~cm}^{-1}$ has been identified as the line located at $252 \mathrm{~cm}^{-1}$ and assigned to wagging $\mathrm{CH}_{2}$ and bending $\mathrm{CH}$ groups $[25,26]$. An overlap between the iPP line located at $250 \mathrm{~cm}^{-1}$ and the $\mathrm{H}$ line at $246 \mathrm{~cm}^{-1}$ is possible in iPPH nanocomposites.

The dependence of the Raman lines position on the loading with halloysite is shown in Figure 2. Empty symbols are connected to the polymeric matrix and solid symbols to the filler. Half-solid symbol is assigned to the overlapping signals. It is noticed that the peak located at $275 \mathrm{~cm}^{-1}$ is shifted towards larger Raman shift. The experimental data indicates a dehydration of the halloysite, expected during the thermal processing of the nanocomposite. It is important 
to mention that in the case of halloysite, the Raman peaks were rather weak. At low concentration of halloysite, the water diffused within the polymer as moisture may hydrate weakly the filler. However, for samples containing $2.5 \%$ wt. $\mathrm{H}$ or a smaller amount of $\mathrm{H}$, the intensity of this line is fairly low. From Figure 2 it is noticed that the position of the Raman lines of $\mathrm{H}$ are displaced towards smaller Raman shifts suggesting a weak dehydration of the nanofiller. This is consistent with the thermal blending and suggests a partial loss of water during the processing of the nanocomposites.

The second spectral domain, ranging between 300 and $500 \mathrm{~cm}^{-1}$, includes both iPP and $\mathrm{H}$ lines, as shown in Figure 3. The line noticed at $335 \mathrm{~cm}^{-1}$ can be assigned to uncomplexed kaolinite [19] or to water in nanoclays (responsible for another Raman line typically located at $332 \mathrm{~cm}^{-1}$ [24]) while the weak and broad line at $389 \mathrm{~cm}^{-1}$ confirms the presence of anatase impurities [19]. The line at $469 \mathrm{~cm}^{-1}$ is tentatively assigned to $\mathrm{Al}-\mathrm{O} / \mathrm{Si}-\mathrm{O}$ vibrations [19] and labeled as the $\mathrm{N}$ line.

There are three main Raman lines, which are typically assigned to iPP in this spectral domain located at about $320 \mathrm{~cm}^{-1}[26,27], 400 \mathrm{~cm}^{-1}[26,27]$, and $455 \mathrm{~cm}^{-1}$ [28]. The line located at about $400 \mathrm{~cm}^{-1}$, assigned to the umbrella bending mode about the tertiary carbon atom [29], is the most intense one. The last line was assigned to wagging $\mathrm{CH}_{2}$ and bending $\mathrm{CH}$ [28]. As noticed in Figure 4, the Raman lines of $\mathrm{H}$ are shifted towards lower Raman shifts as the $\mathrm{H}$ content is increased above $10 \%$ wt. halloysite. The position of the iPP line located at $399 \mathrm{~cm}^{-1}$ shows a weak shift towards larger values as the concentration of halloysite is increased. In the case of the line located at $400 \mathrm{~cm}^{-1}$, it was reported that the melting is shifting this line to $402 \mathrm{~cm}^{-1}$ [28]. This suggests a drop of the degree of crystallinity of iPP upon loading with $\mathrm{H}$. The position of the iPP line located at $455 \mathrm{~cm}^{-1}$ is shifted to lower values as the $\mathrm{H}$ content is increased. The position of the other line assigned to iPP has a complex dependence of $\mathrm{H}$ content showing above $10 \%$ wt. halloysite a weak shift of the line to smaller Raman shifts as the $\mathrm{H}$ content is increased.

Figure 5 collects the line recorded in the spectral domain from $500 \mathrm{~cm}^{-1}$ to $800 \mathrm{~cm}^{-1}$. In this range, several Raman lines are expected. Water (in $\mathrm{H}$ ) can contribute with a weak line located at $789 \mathrm{~cm}^{-1}[21,22]$. The line at $712 \mathrm{~cm}^{-1}$ is a rather weak resonance that confirms the presence of $\mathrm{OH}$ groups [24]. The line noticed at $754 \mathrm{~cm}^{-1}$ is labeled as the $\mathrm{K}$ line [19]. A single strong line due to iPP, located at $525 \mathrm{~cm}^{-1}$ and assigned to wagging $\mathrm{CH}_{2}$, stretching $\mathrm{C}-\mathrm{CH}_{3}$, and rocking $\mathrm{CH}_{2}$ [28]. The effect of the loading of iPP with $\mathrm{H}$ on the most important Raman lines observed in this spectral domain is shown in Figure 6. The position of the line located at $525 \mathrm{~cm}^{-1}$ is almost not modified by the loading with $\mathrm{H}$. The position of the Raman lines assigned to $\mathrm{H}$ shows a complex dependence on the content of $\mathrm{H}$ (at low concentration of $\mathrm{H}$ ) continuing by a weak shift towards larger values (versus $\mathrm{H}$ concentration) for samples containing between 10 and $30 \%$ wt. $\mathrm{H}$.

Figure 7 collects the Raman lines in the spectral domain from 800 to $1000 \mathrm{~cm}^{-1}$. This spectral domain is dominated by the Raman lines due to iPP. The weak Al-OH libration line $[19,24]$ located at $910-912 \mathrm{~cm}^{-1}$ and labeled as the I line is within the noise. The Raman lines originating from iPP have been observed at $808 \mathrm{~cm}^{-1}$ (regularity band associated with crystalline domains reflecting $\mathrm{C}-\mathrm{C}$ stretching along backbone and rocking $\left.\mathrm{CH}_{3}[27,28,30]\right), 840 \mathrm{~cm}^{-1}$ (another regularity band due to $\mathrm{CH}_{3}$ rocking and originating from amorphous regions [28]), $895 \mathrm{~cm}^{-1}$ (rocking $\mathrm{CH}_{2}$, stretching $\mathrm{CH}_{3}$, and bending $\mathrm{CH}$ [28]), and $940 \mathrm{~cm}^{-1}$. The line located at $895 \mathrm{~cm}^{-1}$ is typically observed in melts of iPP. This confirms that the loading of iPP with halloysite drops the degree of crystallinity of the polymeric matrix and agrees with experimental data on iPP filled with VGCNFs $[11,12]$. Figure 8 shows the effect of the loading with $\mathrm{H}$ on the position of various Raman lines. The figure includes a single line assigned to $\mathrm{H}$, which is weakly shifted towards larger values. The shift is stronger for $\mathrm{H}$ concentrations larger than 10\% wt. (At low $\mathrm{H}$ concentrations the shift towards larger values is slightly above the experimental errors). The iPP lines included in Figure 8 are almost independent on the concentration of $\mathrm{H}$.

The Raman spectra in the range from $1000 \mathrm{~cm}^{-1}$ to $1100 \mathrm{~cm}^{-1}$ are shown in Figure 9. This spectral domain is dominated by the strong lines originating from iPP and located at $972 \mathrm{~cm}^{-1}$ (regularity band due to $\mathrm{CH}_{3}$ rocking $[27,28]$ ), $997 \mathrm{~cm}^{-1}$ (another regularity band that does not disappear on melting [28]), $1033 \mathrm{~cm}^{-1}$ (which was reported as a structural defect [28]), $1041 \mathrm{~cm}^{-1}$, and $1100 \mathrm{~cm}^{-1}$. Halloysite is responsible for two weak lines located at $1172 \mathrm{~cm}^{-1}$ and $1180 \mathrm{~cm}^{-1}$ assigned to Si-O units [22]. The effect of loading with $\mathrm{H}$ on the position of the Raman lines is shown in Figure 10. The spectra assigned to iPP are shifted towards larger Raman shifts as the content of halloysite is increased. Nevertheless, these shifts are rather weak. The dependence of the position of the halloysite limes on the content of halloysite is complex and weak. The line located at $1033 \mathrm{~cm}^{-1}$ indicates the enhancement of structural defects in $\mathrm{H}$-doped nanocomposites. Nevertheless, the broadening of this line makes difficult an accurate estimation of the dependence of disorder degree versus the concentration of halloysite.

The isotacticity was calculated as the ratio between the area of the peak located at $809 \mathrm{~cm}^{-1}$ and the area of the peak located at $974 \mathrm{~cm}^{-1}$ [27]. Figure 11 demonstrates the drop of the isotacticity index as the polymeric matrix is loaded with $\mathrm{H}$, indicating a decrease of the degree of crystallinity, consistent with other features noticed within this study.

The thermal stability of halloysite is rather poor. As can be inferred from Figure 12, the TGA data of pristine halloysite are consistent with stepwise thermal degradations centered at $250^{\circ} \mathrm{C}, 480^{\circ} \mathrm{C}$, and $680^{\circ} \mathrm{C}$. The first maxim is assigned to the loss of crystallization water and the second one is assigned to dehydroxilation towards kaolinite (actually metakaolin, $\mathrm{Al}_{2} \mathrm{Si}_{2} \mathrm{O}_{7}$ ). Assuming that all crystallization data is lost at $300^{\circ} \mathrm{C}$, the corrected structure of the pristine halloysite is $\mathrm{Al}_{2} \mathrm{Si}_{2} \mathrm{O}_{5}(\mathrm{OH})_{4} \cdot x \mathrm{H}_{2} \mathrm{O}$, where $x=0.5$.

Raman spectra of pristine and annealed halloysite shown in Figure 13 exibit small differences, probably because the main component is the dehydrated halloysite and the recorded spectra are actually convolutions over slightly 


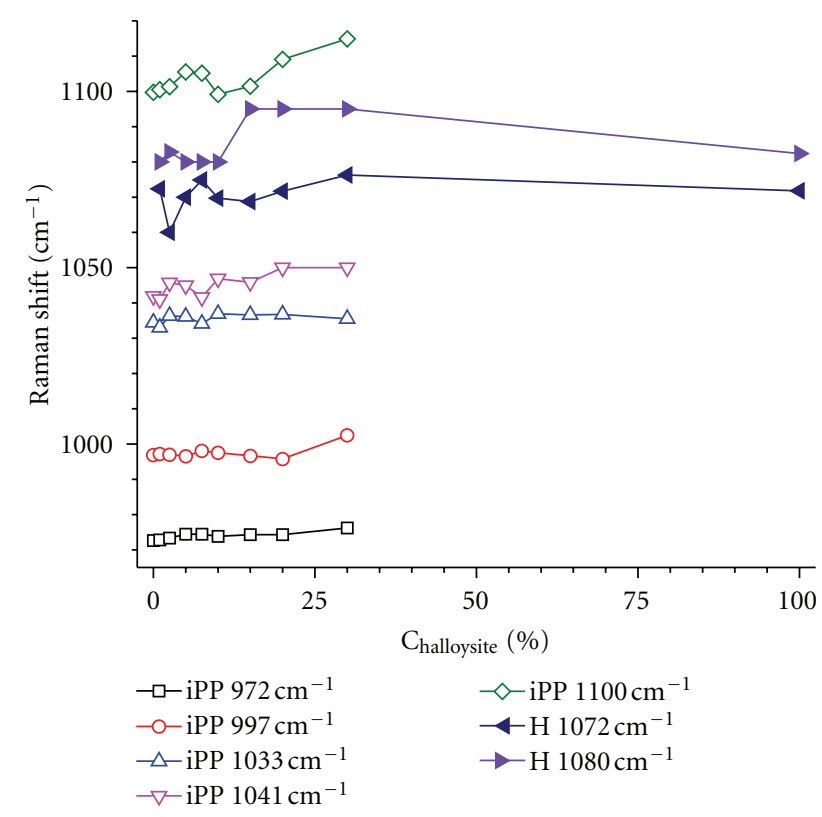

FIgure 10: The effect of the loading with $\mathrm{H}$ on the position of Raman lines in the range from 1000 to $1100 \mathrm{~cm}^{-1}$. iPP (or open symbols) identifies the Raman lines assigned to the matrix, and $\mathrm{H}$ the Raman lines due to the filler.

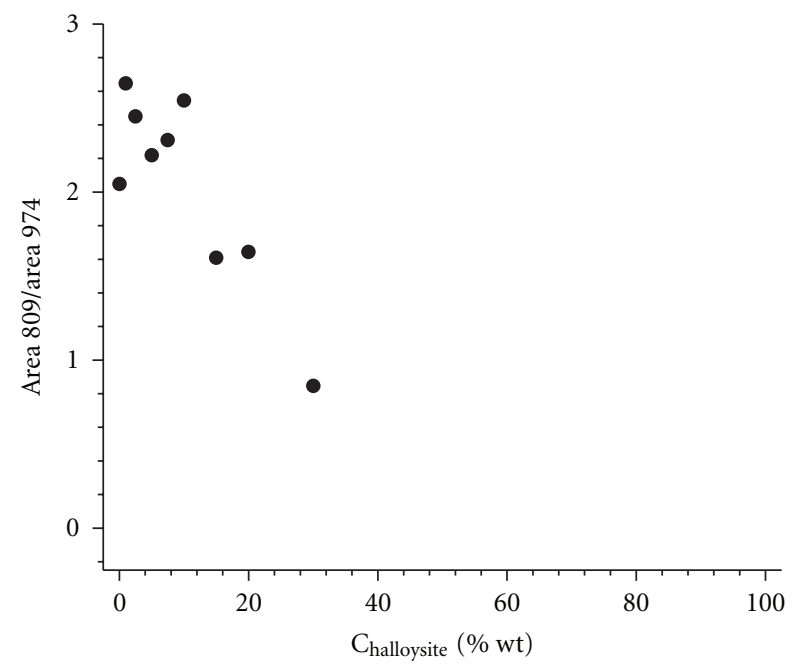

FIGURE 11: The dependence of the isotacticity index (i.e., of the ratio between the areas of the peaks located at 809 and $974 \mathrm{~cm}^{-1}$ on the loading with halloysite).

different structures. Figure 14 collects the Raman spectra of iPPH nanocomposites annealed at $250^{\circ} \mathrm{C}$ for 30 minutes. It is noticed that the annealing at $250^{\circ} \mathrm{C}$ (i.e., the dehydration of the halloysite) has a weak effect on the Raman spectra of iPPH nanocomposites.

\section{Conclusions}

Raman spectroscopy investigations on nanocomposites obtained by dispersing halloysite within iPP are reported.

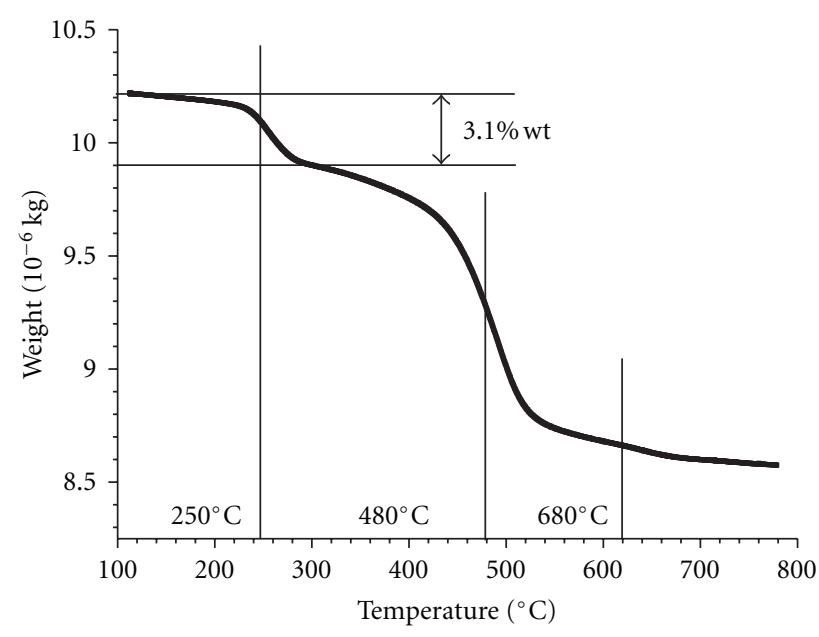

Figure 12: TGA data of pristine halloysite showing the main thermal degradation processes.

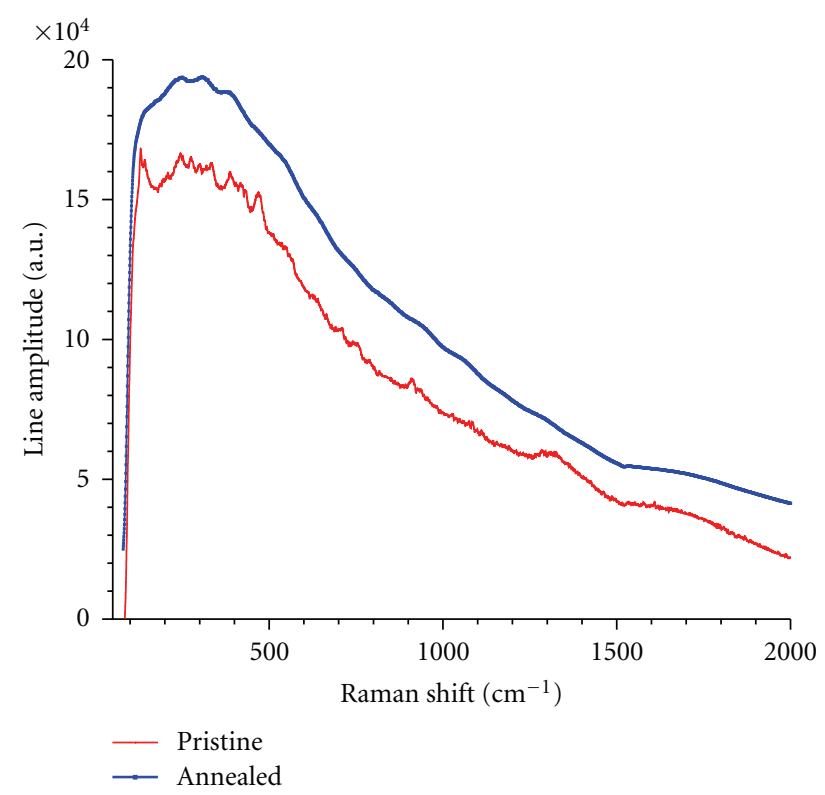

FIGURE 13: The Raman spectrum of pristine halloysite (narrow line) and of the halloysite annealed for 30 minutes at $250^{\circ} \mathrm{C}$.

The Raman lines of halloysite are broad, as the experimental spectra are a convolution of spectra corresponding to molecules with various degrees of hydration. TGA data suggested that in average each two molecules of halloysite contain one molecule of water (or in other words there is one molecule of halloysite $10 \mathrm{~A}$ to every 4 molecules of halloysite $7 \mathrm{~A}$ ). The existing literature suggests that the Young modulus of halloysite is three times smaller than the Young modulus of carbon nanotubes. For the same applied stress, the estimated strain should be three times larger than in carbon nanotubes. Hence, larger Raman shifts were expected in iPPH nanocomposites than in iPP-VGCNF composites. By comparing the Raman shifts reported here to the Raman shifts noticed in our previous study of iPP-VGCNF [11], it is 


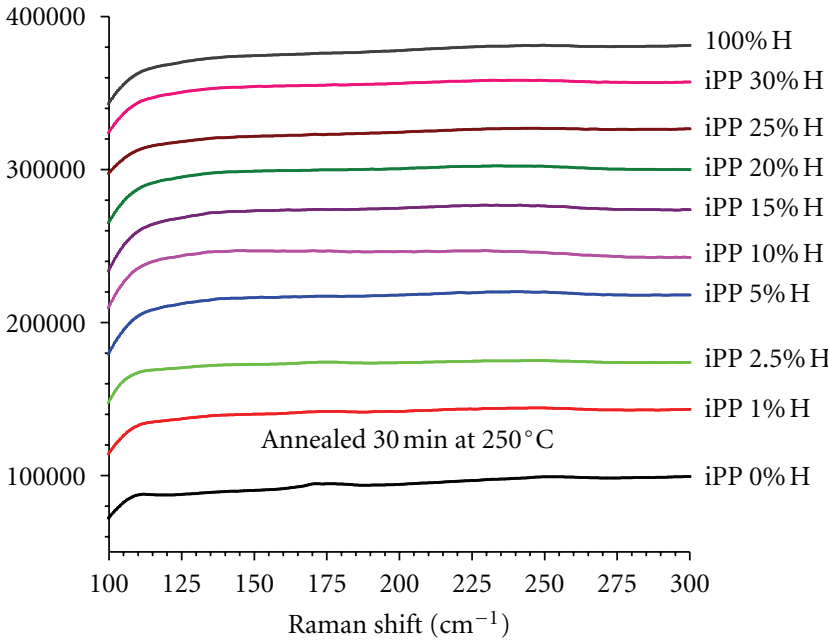

(a)

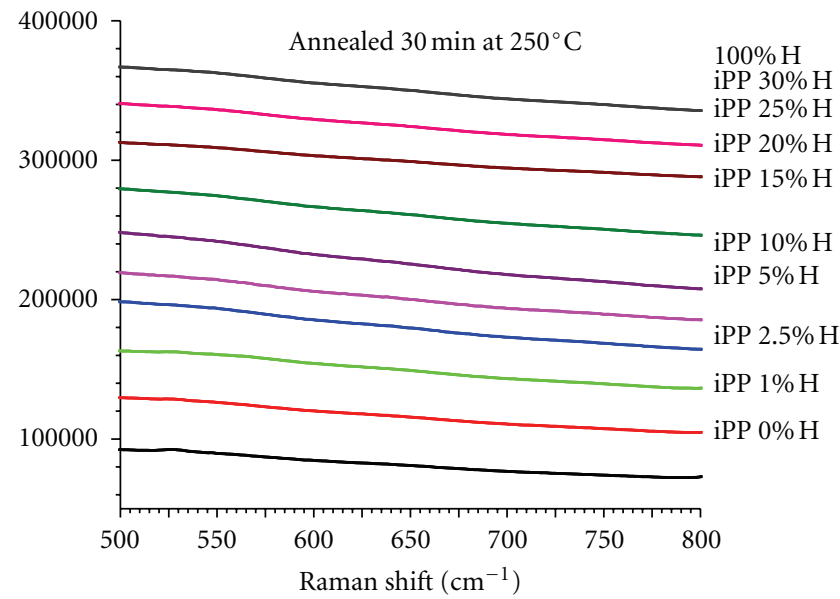

(c)

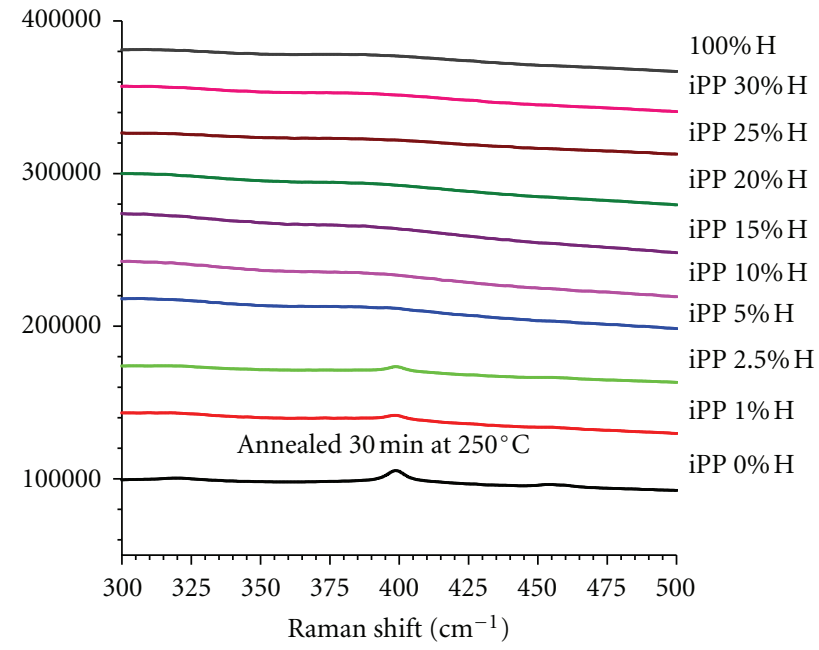

(b)

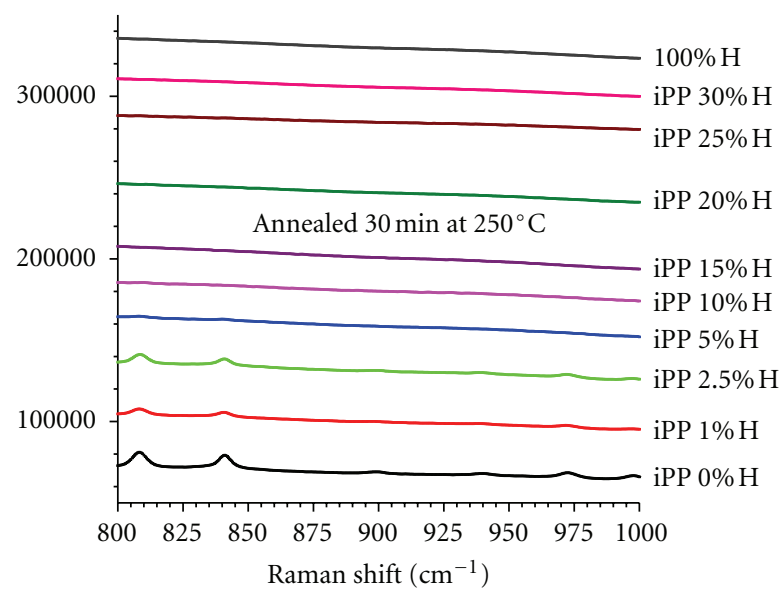

(d)

FIGURE 14: The Raman spectra of iPPH nanocomposites annealed at $250^{\circ}$ for 30 minutes.

concluded that the shifts of the Raman peaks as a function of filler's concentration are weaker for halloysite (compared to VGCNF), and consequently the stress transfer between the polymeric matrix (same iPP) and the nanofiller is less efficient in the case of halloysite.

The experimental data are qualitatively analogous with the iPP-VGCNF nanocomposites; the nanofiller broadens and decreases the intensity of the Raman lines assigned to the polymeric matrix (iPP). However, due to the fact the nanofiller does not exhibit narrow and strong Raman lines, the analysis was also focused on the polymeric matrix. A detailed analysis of the modifications of the regularity band associated to the polymeric matrix is presented. The analysis of Raman lines indicates that the polymeric matrix becomes less crystalline upon the loading with halloysite and that the nanofiller is experiencing a weak dehydration upon dispersion within the polymeric matrix, probably due to the thermal processing. Raman spectroscopy failed to substantiate the growth of a gamma iPP phase due to the loading of isotactic polypropylene with halloysite as reported in [14]. In conclusion, in iPP the loading with halloysite drops the isotacticity and decreases the degree of crystallinity, in contrast with the data reported in [14]. The drop of the isotacticity of $\mathrm{iPP}$ as the concentration of $\mathrm{H}$ is increased demonstrates interactions between the polymeric matrix and the halloysite nanotubes. As discussed previously, these interactions are weaker than in iPP-VGCNF nanocomposite. Further Differential Scanning Calorimetry and Wide Angle $\mathrm{X}$-Ray Scattering experiments are in course to address the crystallinity and the crystallization of these nanocomposites.

\section{Acknowledgments}

This work was supported by the National Science Foundation under DMR Grant no. 0934157 (PREM-The University of Texas-Pan American (UTPA)/University of MinnesotaScience and Engineering of Polymeric and NanoparticleBased Materials for Electronic and Structural Applications). 


\section{References}

[1] V. Chirila, G. Marginean, T. Iclanzan, C. Merino, and W. Brandl, "Method for modifying mechanical properties of carbon nano-fiber polymeric composites," Journal of Thermoplastic Composite Materials, vol. 20, no. 3, pp. 277-289, 2007.

[2] K. Suzuki and S. Nomura, "On elastic properties of singlewalled carbon nanotubes as composite reinforcing fillers," Journal of Composite Materials, vol. 41, no. 9, pp. 1123-1135, 2007.

[3] K. T. Lau, M. Chipara, H. Y. Ling, and D. Hui, "On the effective elastic moduli of carbon nanotubes for nanocomposite structures," Composites B, vol. 35, no. 2, pp. 95-101, 2004.

[4] F. Hussain, M. Hojjati, M. Okamoto, and R. E. Gorga, "Review article: polymer-matrix nanocomposites, processing, manufacturing, and application: an overview," Journal of Composite Materials, vol. 40, no. 17, pp. 1511-1575, 2006.

[5] A. Allaoui, S. V. Hoa, and M. D. Pugh, "The electronic transport properties and microstructure of carbon nanofiber/epoxy composites," Composites Science and Technology, vol. 68, no. 2, pp. 410-416, 2008.

[6] J. Bernholc, D. Brenner, M. Buongiorno Nardelli, V. Meunier, and C. Roland, "Mechanical and electrical properties of nanotubes," Annual Review of Materials Science, vol. 32, pp. 347375, 2002.

[7] J. Li and J. K. Kim, "Percolation threshold of conducting polymer composites containing 3D randomly distributed graphite nanoplatelets," Composites Science and Technology, vol. 67, no. 10, pp. 2114-2120, 2007.

[8] N. Li, Y. Huang, F. Du et al., "Electromagnetic Interference (EMI) shielding of single-walled carbon nanotube epoxy composites," Nano Letters, vol. 6, no. 6, pp. 1141-1145, 2006.

[9] A. R. Bhattacharyya, T. V. Sreekumar, T. Liu et al., "Crystallization and orientation studies in polypropylene/single wall carbon nanotube composite," Polymer, vol. 44, no. 8, pp. 2373-2377, 2003.

[10] E. Logakis, E. Pollatos, C. Pandis et al., "Structure-property relationships in isotactic polypropylene/multi-walled carbon nanotubes nanocomposites," Composites Science and Technology, vol. 70, no. 2, pp. 328-335, 2010.

[11] C. Mircea, J. R. Villarreal, M. D. Chipara, K. Lozano, A. C. Chipara, and D. J. Sellmyer, "Spectroscopic investigations on polypropylene-carbon nanofiber composites. I. Raman and electron spin resonance spectroscopy," Journal of Polymer Science B, vol. 47, no. 17, pp. 1644-1652, 2009.

[12] M. D. Chipara, K. Lozano, A. Hernandez, and M. Chipara, "TGA analysis of polypropylene-carbon nanofibers composites," Polymer Degradation and Stability, vol. 93, no. 4, pp. 871876, 2008.

[13] M. Chipara, J. Hamilton, A. C. Chipara, T. George, D. M. Chipara, E. E. Ibrahim et al., "Fourier transform infrared spectroscopy and wide-angle X-ray scattering: investigations on polypropylene-vapor-grown carbon nanofiber composites," Journal of Applied Polymer Science, vol. 125, no. 1, pp. 353-360, 2012.

[14] M. Du, B. Guo, and D. Jia, "Newly emerging applications of halloysite nanotubes: a review," Polymer International, vol. 59, no. 5, pp. 574-582, 2010.

[15] Y. Tang, S. Deng, L. Ye et al., "Effects of unfolded and intercalated halloysites on mechanical properties of halloysite-epoxy nanocomposites," Composites A, vol. 42, no. 4, pp. 345-354, 2011.
[16] E. Horváth, J. Kristóf, R. Kurdi, É. Makó, and V. Khunová, "Study of urea intercalation into halloysite by thermoanalytical and spectroscopic techniques," Journal of Thermal Analysis and Calorimetry, vol. 105, no. 1, pp. 53-59, 2011.

[17] B. Lecouvet, M. Sclavons, S. Bourbigot, J. Devaux, and C. Bailly, "Water-assisted extrusion as a novel processing route to prepare polypropylene/halloysite nanotube nanocomposites: structure and properties," Polymer, vol. 52, no. 19, pp. 42844295, 2011.

[18] L. Guimarães, A. N. Enyashin, G. Seifert, and H. A. Duarte, "Structural, electronic, and mechanical properties of singlewalled halloysite nanotube models," Journal of Physical Chemistry C, vol. 114, no. 26, pp. 11358-11363, 2010.

[19] K. H. Michaelian, S. L. Zhang, S. Yariv, and I. Lapides, "Lowfrequency Raman spectra of kaolinite/alkali halide complexes," Applied Clay Science, vol. 13, no. 4, pp. 233-243, 1998.

[20] S. D. M. Brown, A. Jorio, P. Corio et al., "Origin of the BreitWigner-Fano lineshape of the tangential G-band feature of metallic carbon nanotubes," Physical Review B, vol. 63, no. 15, Article ID 155414, pp. 1554141-1554148, 2001.

[21] R. L. Frost and H. F. Shurvell, "Raman microprobe spectroscopy of halloysite," Clays and Clay Minerals, vol. 45, no. 1, pp. 68-72, 1997.

[22] R. L. Frost, T. H. Tran, and J. Kristof, "FT-Raman spectroscopy of the lattice region of kaolinite and its intercalates," Vibrational Spectroscopy, vol. 13, no. 2, pp. 175-186, 1997.

[23] R. L. Frost, "Fourier transform Raman spectroscopy of kaolinite, dickite and halloysite," Clays and Clay Minerals, vol. 43, no. 2, pp. 191-195, 1995.

[24] J. T. Kloprogge and R. L. Frost, "Raman microprobe spectroscopy of hydrated halloysite from a neogene cryptokarst from Southern Belgium," Journal of Raman Spectroscopy, vol. 30, no. 12, pp. 1079-1085, 1999.

[25] M. Arruebarrena de Báez, P. J. Hendra, and M. Judkins, "The Raman spectra of oriented isotactic polypropylene," Spectrochimica Acta A, vol. 51, no. 12, pp. 2117-2124, 1995.

[26] T. Hahn, W. Suen, S. Kang, S. L. Hsu, H. D. Stidham, and A. R. Siedle, "An analysis of the Raman spectrum of syndiotactic polypropylene. 1. Conformational defects," Polymer, vol. 42, no. 13, pp. 5813-5822, 2001.

[27] T. Sundell, H. Fagerholm, and H. Crozier, "Isotacticity determination of polypropylene using FT-Raman spectroscopy," Polymer, vol. 37, no. 15, pp. 3227-3231, 1996.

[28] R. M. Khafagy, "In situ FT-Raman spectroscopic study of the conformational changes occurring in isotactic polypropylene during its melting and crystallization processes," Journal of Polymer Science B, vol. 44, no. 15, pp. 2173-2182, 2006.

[29] V. M. Hallmark, S. P. Bohan, H. L. Strauss, and R. G. Snyder, "Analysis of the low-frequency isotropic Raman spectrum of molten isotactic polypropylene," Macromolecules, vol. 24, no. 14, pp. 4025-4032, 1991.

[30] D. E. Gen, K. A. Prokhorov, G. Y. Nikolaeva et al., "Raman spectra of various polymorphs of isotactic polypropylene," Laser Physics, vol. 21, no. 1, pp. 125-129, 2011. 

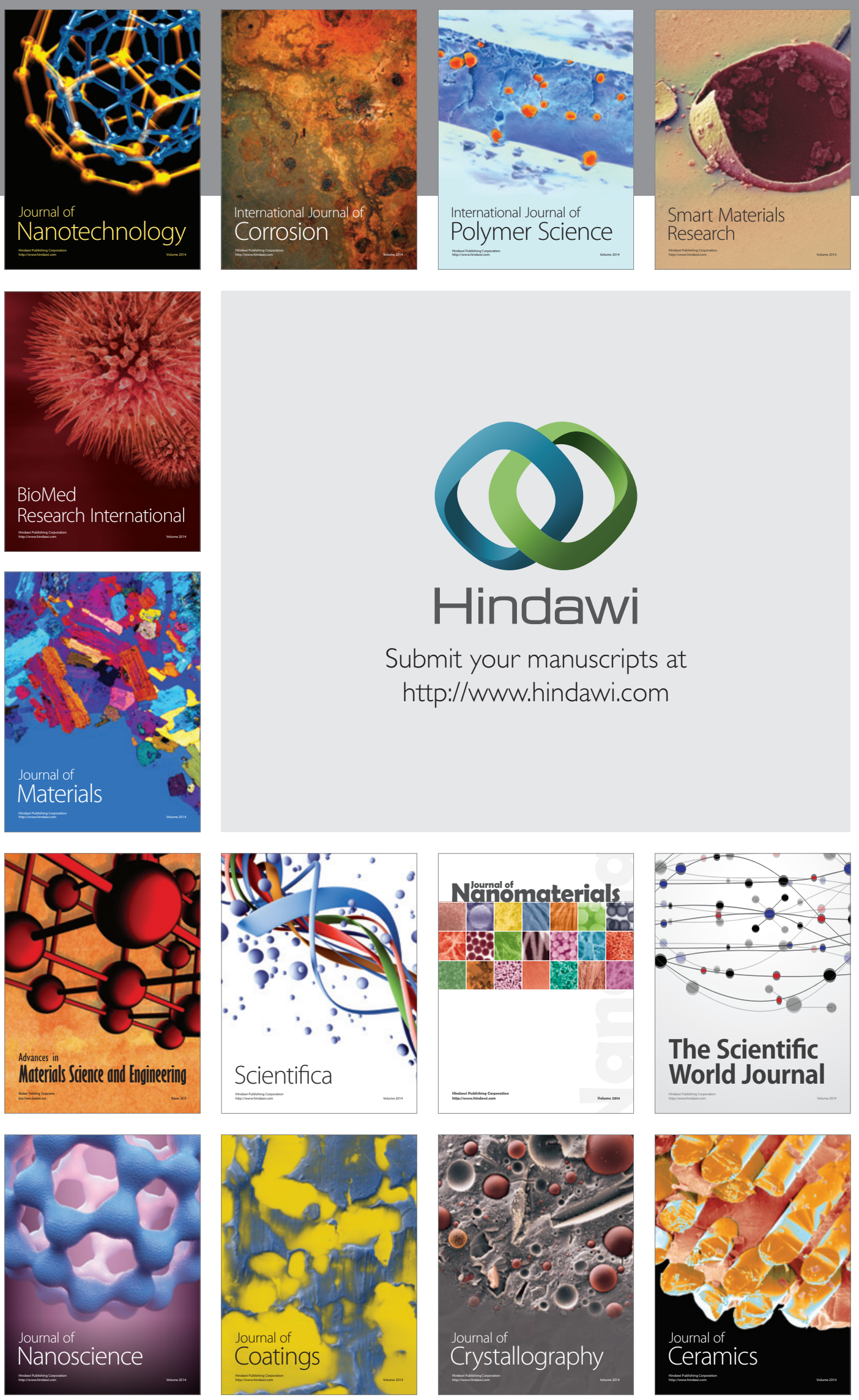

The Scientific World Journal

Submit your manuscripts at

http://www.hindawi.com

\section{World Journal}

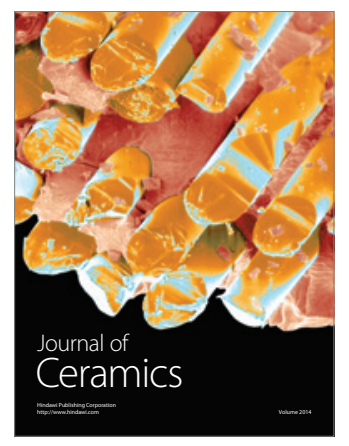

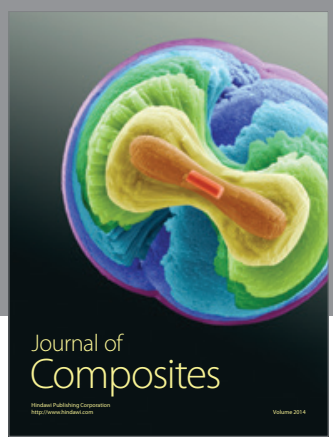
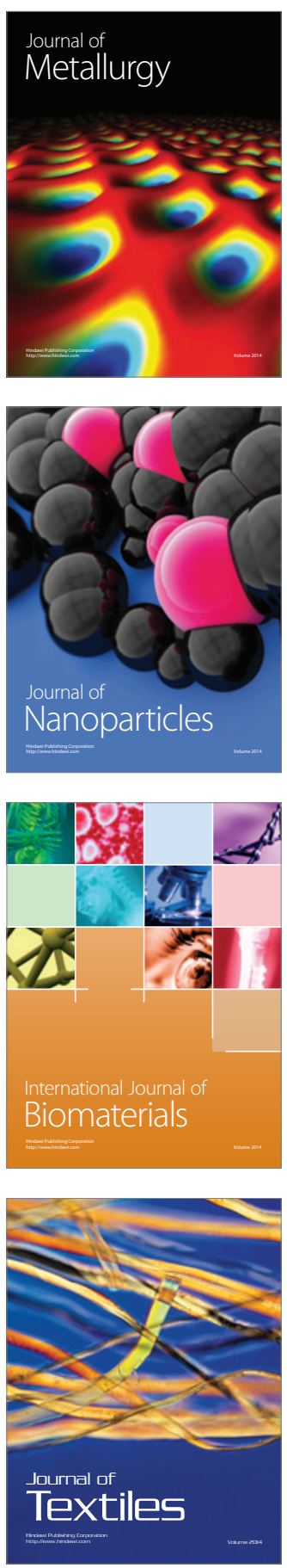